\title{
IMPROVING THE CHARACTERISTICS OF PNEUMATIC TRANSPORT OF GRAIN
}

\author{
Predrag Mošorinski* \\ Technical school Zrenjanin, Serbia \\ Slavica Prvulović \\ University of Novi Sad, Technical faculty "Mihajlo Pupin” Zrenjanin, Serbia \\ Ivan Palinkaš \\ University of Novi Sad, Technical faculty "Mihajlo Pupin" Zrenjannin, Serbia
}

Pneumatic transport is the most commonly performed transport of fine-grained and powder materials to manufacturing plants. It is considered that this is the most applicable transport within the manufacturing companies for the processing of grain and powder materials. The need for this kind of transport to be more sustainable, improved and to perfect encouraged the authors of this paper to address this issue. It is assumed that at a certain point transport system choked due to unforeseen circumstances so it is necessary to make urgent additional works to be returned to the operating mode of the system. Tendency is to make the system predictable and downtime to a minimum.

Key words: Pneumatic transport, Granular materials, Oilseeds, Damaged grains, Pipe system

\section{INTRODUCTION}

The basic tendency of pneumatic transport is to be the most economical and more flexible with the use of a high level of process automation in compare to other types of transport like screw or belt conveyors [01, 09]. The environmental demands that are presumed today just favor this kind of transport in relation to others and make it the only possible thing in a particular technological process, since the transport is carried out by pipes and there is no waste of material and therefore environmental pollution.

In comparison of the pneumatic transport with mechanical, numerous advantages can be seen. Pneumatic transport can be carried out in all directions, adapting to the available space and other conditions. It requires less space and provides ability to connect different segments in process due to technological requirements (drying or moistening of materials during transport, simultaneous heating or cooling air, sorting material by size of grain based on deposition rate, etc.). Applying the vacuum process the environmental requirements are meet (less air pollution). Pneumatic transport provides a high degree of automation of the process and it can be positioned in numerous places simultaneously and thereby enabling transport of large amount of material in short time.

Pneumatic transport within the factory, which is engaged in processing oilseeds, is faced with many problems. By conducting oil seeds from the silo to the production line comes to significant damage to the piping system because of the shock of grain on the walls of the pipe. The worst damage can be seen on elbow pipes, since the wiring system is combined with the movement of the grains in the horizontal and in the vertical direction. Speed of impact and the amount of grain in a given time interval are the causes of deformation and failure within the transport system. Experience has proven to overhaul this system must be carried out over a period of 6 to 8 months and constantly have to combine materials to pipe installations withstood high speed shocks of grain for a longer period of time. The process rebuilds due to failure lasts up to several days, which represents a high cost for producers. It is necessary to predict system failures and reduce them to a minimum during a longer time interval. It is believed this problem can be successfully solved by the introduction of new technologies, which would reduced the number of failures to minimize in the medium-term production planning (1-5 years of exploitation). This would practically overhaul of the transport system reduced to a regular (annual) period with 
significantly lower total cost of production.

The need for the system to the introduction of grains into the transport system and flow through a system (discontinuous and turbulent) is reduced to continuous, to give a more balanced effect of the shock on the walls of the tube system. The grain is irregular in shape with certain impurities (skinned), and each attack creates the effect of a bullet strikes causing major damage to a small area. In order to mitigate this effect, it is necessary to group the grains in the cross section of the pipe system and reduce the speed of impact of the crossing points (elbows) and thus achieved the effect of superficial attack with minor consequences. To achieve this effect in the transport system should be controlled and synchronized multiple parameters in a short time interval. Using the Venturi injector, at the beginning of the pneumatic lines, can significantly improve and speed up the flow and thereby improve the dosing grains with significant control the speed of movement of grain.

\section{TECHNICAL CONDITIONS OF PNEUMATIC TRANSPORT IN FACTORY FOR PRODUCTION OF EDIBLE OILS}

Pneumatic transport of granular materials, sunflower and soya, is organized so that the silo granular material leads to the central doser, and then the method of free fall granular material falls into the dispenser thrusters air-blowers (compressors), as shown in (Figure 1) [07]. Blowers uppresses the granular material through a pneumatic system to a processing plant peeling. Working pressure blowers is 0.35 bar and the capacity of 30 tons of sunflower or 25 tons of soy per hour. The compressor products operating pressure of 1.5 bar that reduce the required 0.5 bar. The compressor is from a group of rotary compressor with profile rotary pistons. The microprocessor is configured to exclude the compressor at a pressure of 0.7 bar, in order to avoid overloading and heating. Through the installation of pneumatic granular material flows at high speed flow in order to provide the required capacity of the materials.

Pipe installation of pneumatic system consists of seamless pipe diameter $\varnothing 176 \mathrm{~mm}$, a length of about 70 meters, with multiple crossings of the horizontal to the vertical part of the transport system. Transitions (knee) pipe systems are made of curved pipe with flanges on both ends and made an angle of 90 and crossing radius of $1800 \mathrm{~mm}$. The system extends from the blower to plant for peeling grains and partly exposed to the outside temperature and weather influences [07].

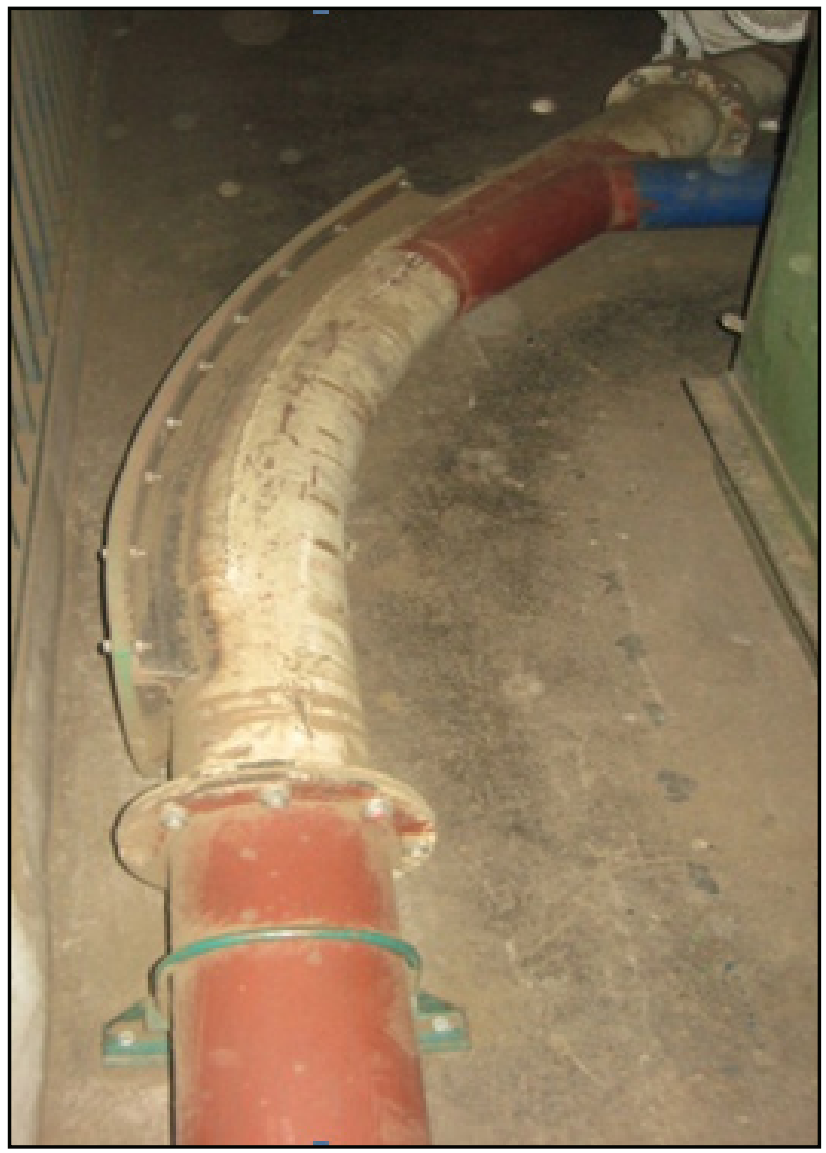

Figure 1: Knee reinforced with PE 1000

\section{TECHNICAL CHARACTERISTICS OF THE BLOWERS}

Aggregate from the manufacturer of blowers is designed to provide air flow high capacity at low differential pressure. The unit is supplied as a pusher air (blower) with regulation of negative pressure or vacuum pump. Some types of blowers with the given operating limits are shown in the Table (Table 1) and the installed type is $\mathrm{SNH}$ $825 \mathrm{~m}$. 
Table 1: Some types of blowers with the given operating limits

\begin{tabular}{|c|c|c|c|c|c|c|c|c|c|}
\hline \multirow{2}{*}{ Type blowers } & \multicolumn{2}{|c|}{ Rpm } & \multirow{2}{*}{$\begin{array}{c}\Delta p \\
\text { (bar) }\end{array}$} & \multirow{2}{*}{$\begin{array}{c}\text { flow } \\
\left(\mathrm{m}^{3} / \mathrm{h}\right)\end{array}$} & \multirow{2}{*}{$\begin{array}{c}\text { vacuum } \\
\text { (bar) }\end{array}$} & \multicolumn{2}{|c|}{$\mathrm{t} 1\left({ }^{0} \mathrm{C}\right)$} & \multirow[t]{2}{*}{$\mathrm{t} 2\left({ }^{0} \mathrm{C}\right)$} & \multirow{2}{*}{$\begin{array}{c}\text { power } \\
(\mathrm{kW})\end{array}$} \\
\hline & $\max$ & $\min$ & & & & $\max$ & $\min$ & & \\
\hline SNH804MA & 4100 & 1200 & 1 & 960 & 0,5 & 50 & -25 & 140 & 37 \\
\hline SNH806MA & 3800 & 1200 & 1,1 & 1380 & 0,5 & 50 & -25 & 140 & 45 \\
\hline SNH809MA & 3800 & 1200 & 0,9 & 1950 & 0,5 & 50 & -25 & 140 & 75 \\
\hline SNH811MA & 3800 & 1200 & 1 & 2390 & 0,5 & 50 & -25 & 140 & 90 \\
\hline SNH817MA & 3300 & 1200 & 1,1 & 3180 & 0,5 & 50 & -25 & 140 & 90 \\
\hline SNH822MA & 3300 & 1200 & 0,8 & 4550 & 0,5 & 50 & -25 & 140 & 132 \\
\hline SNH825MA & 2960 & 720 & 1,1 & 4220 & 0,5 & 50 & -25 & 140 & 132 \\
\hline SNH842MA & 2250 & 720 & 0,93 & 5100 & 0,5 & 50 & -25 & 140 & 132 \\
\hline
\end{tabular}

Where: $\Delta p$ (bar) - the difference between the absolute pressure on the pressure side and suction $\left(1 \mathrm{bar}=1 \times 10^{5} \mathrm{~Pa}\right)$

- $\mathrm{t}_{1}\left({ }^{0} \mathrm{C}\right)$ - the temperature of the intake

- $t_{2}\left({ }^{0} \mathrm{C}\right)$ - the temperature of the propulsor

In the Table 2 contains the values of flow and power absorption for the pressure of a device SNH825MA.

Table 2: Performance blowers type SNH825MA

\begin{tabular}{|c|c|c|c|c|c|c|c|c|c|c|c|c|c|}
\hline \multirow{3}{*}{$\mathrm{rpm}$} & \multicolumn{10}{|c|}{ Flow $\left(\mathrm{m}^{3} / \mathrm{h}\right)$ and power assorbed. $(\mathrm{W})$ of the set pressure } & \multirow{2}{*}{\multicolumn{3}{|c|}{$\begin{array}{l}\text { Maximum } \\
\text { vacuum }\end{array}$}} \\
\hline & \multicolumn{2}{|c|}{$0,4 \mathrm{bar}$} & \multicolumn{2}{|c|}{$0,5 \mathrm{bar}$} & \multicolumn{2}{|c|}{$0,7 \mathrm{bar}$} & \multicolumn{2}{|c|}{$0,8 \mathrm{bar}$} & \multicolumn{2}{|c|}{$0,9 \mathrm{bar}$} & & & \\
\hline & $\mathrm{m}^{3} / \mathrm{h}$ & $\mathrm{kW}$ & $\mathrm{m}^{3} / \mathrm{h}$ & $\mathrm{kW}$ & $\mathrm{m}^{3} / \mathrm{h}$ & $\mathrm{kW}$ & $\mathrm{m}^{3} / \mathrm{h}$ & $\mathrm{kW}$ & $\mathrm{m}^{3} / \mathrm{h}$ & $\mathrm{kW}$ & bar & $\mathrm{m}^{3} / \mathrm{h}$ & kW \\
\hline 720 & 693 & 13.3 & 642 & 16.6 & 553 & 23.3 & - & - & - & - & 0,4 & 569 & 13.3 \\
\hline 1280 & 1560 & 23.6 & 1508 & 29.5 & 1417 & 41.3 & 1376 & 47.2 & 1338 & 53.1 & 0,4 & 1434 & 23.6 \\
\hline 2120 & 2861 & 39.1 & 2807 & 48.9 & 2713 & 68.4 & 2671 & 78.2 & 2632 & 88 & 0,5 & 2599 & 48.9 \\
\hline 2960 & 4162 & 54.6 & 4106 & 68.2 & 4009 & 95.5 & 3966 & 109 & 3925 & 123 & 0,5 & 3891 & 68.2 \\
\hline
\end{tabular}

\section{ANALYSIS OF THE PNEUMATIC SYSTEM}

Pneumatic system periodically cleans and monitors the ultrasound method to avoid congestion process during the process of exploitation. The specificity of the horizontal water pipe system is that it is built from the composite (concrete) coated with sheet in order to minimize fraying in the flow of grain. Soybean and sunflower are very harsh in its raw state, under the assumed humidity defined in the purchase (optimal 15\%) and uneven shape.

Such grains during transport, usually moving on the lower part of the inner piping system and significantly damage the system. Empirical method is determined by the percentage of damage for a certain period so that the tube is rotated peri- odically to 180 degrees and thus extends the lifetime.

Deformation detected on his knees pneumatic systems are much more serious problem and occurs in multiple shorter service life. Reducing the number of failures achieved by installing crash cushions and extending the assumed period of reparation. Mitigation of failures is made of different materials by strengthening and extending the assumed period of reparation. Reinforcements were made materials PE 1000 (Figure 1) who has given good practical results.

The choice of material is defined according to the diagram in Figure 2. Brittle materials are avoided due to dynamic loading system while 
tough and soft (elastomer) because of poor mechanical properties and formability, particularly due to external temperature variations during seasonal changes.

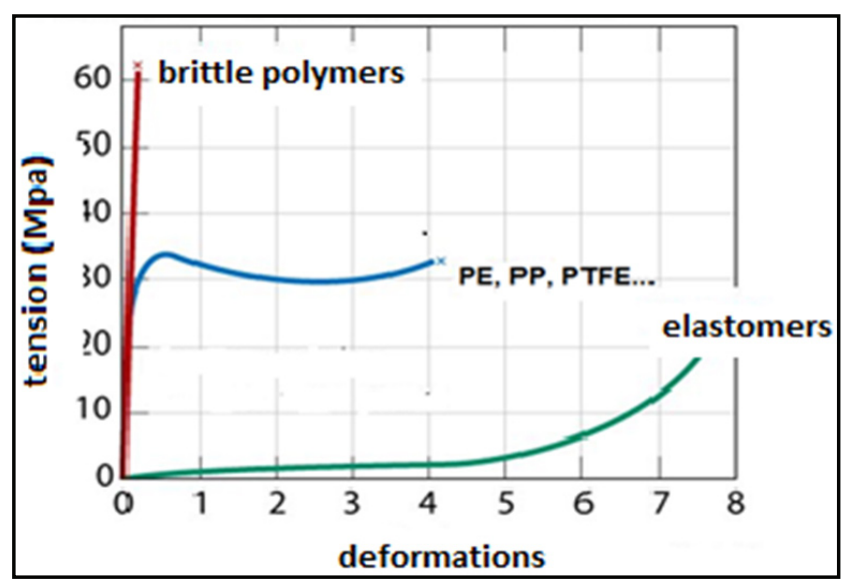

Figure 2: Diagram of the tension - deformation for polymers [04]

According to the laws of movement of grain through the pneumatic system [02, 08], the grain moves turbulent, hitting the walls bend, bouncing off each other and colliding with the consequent slowing of movement and change of continuity of movement. This chaotic movement causes discontinuity of flow and, ultimately, leads to congestion (Figure 3).

The consequences of the arrival of the grain mass at the crossings is increased friction between the grain and the walls of the pass due to the direction of movement and effects of centrifugal force. Even according to some studies detected the collision zone of grain coming out of the bend pipe (secondary collision zone) which results in a slowing of movement and potential fracture grain [03].

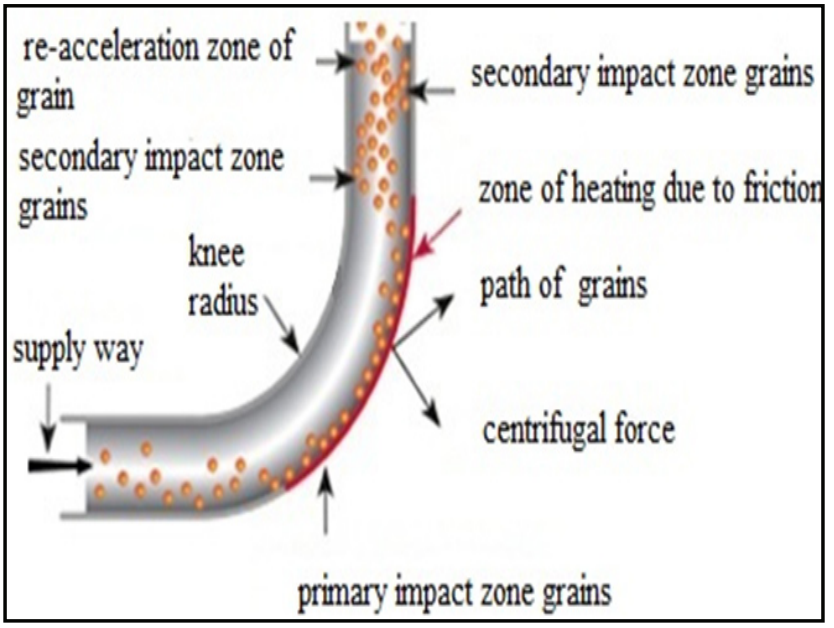

Figure 3: Principle of movement of grain through the elbow [11]
These are the main causes of deformation and there are multiple solutions: adjustment of the pneumatic system with modern shapes of elbows, installation of the Venturi pipe directly below grain dinspenser in order to obtain sufficient speed at the beginning of movement, precise regulation of air and grain velocity through pipe, etc.

\section{IMPROVING THE MOVEMENT OF GRAIN THROUGH THE PNEUMATIC SYSTEM}

Improving the flow of grain through the pneumatic system is conditioned by maintaining the desired and projected daily capacity required for uninterrupted production. The former principle of dosing (Figure 4a) has given good results in terms of design capacity, but with the consequence of significant damage to the piping system for a certain period of exploitation. Draft decision are primarily related to the installation of the Venturi injectors [10] at the entrance to the pneumatic system (Figure $4 \mathrm{~b}$ ) a directly under the collector. This solution would be accelerated at the beginning of grain getting into a tube system and slow moving design speed evenly over the whole cross-section. Flow is hereby improves by $50 \%$ and even up to $80 \%$ with the elimination of all phenomena that negatively affect it [02].

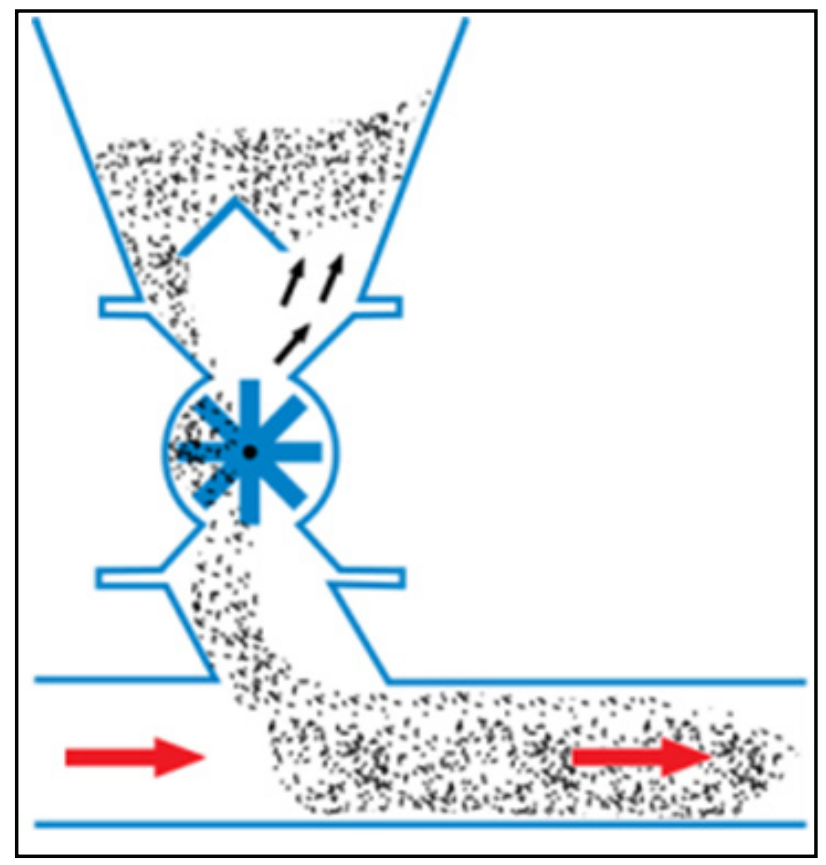

a) Rotation injector

Figure 4a: The reduction the speed of movement of grain [10] 


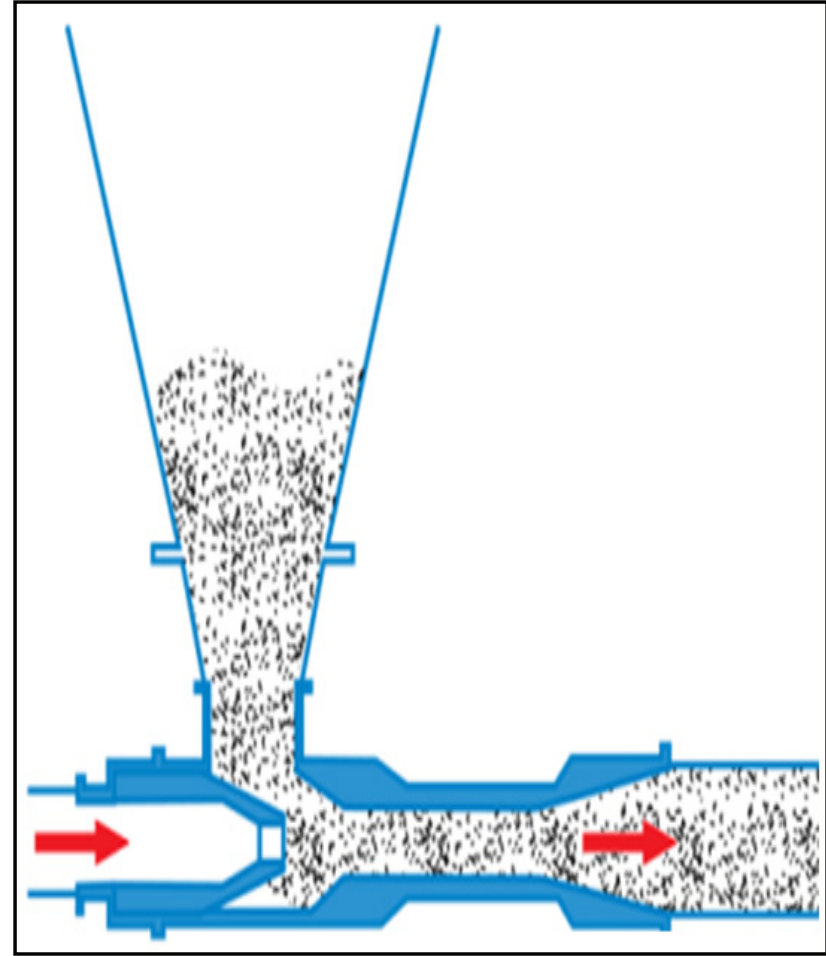

b) Venturi injector

Figure 4b: The reduction the speed of movement of grain [10]

Grain flow is caused by the speed of air flow through the pipe system and the principle of movement is presented in Figure 5 [01, 02, and 03].

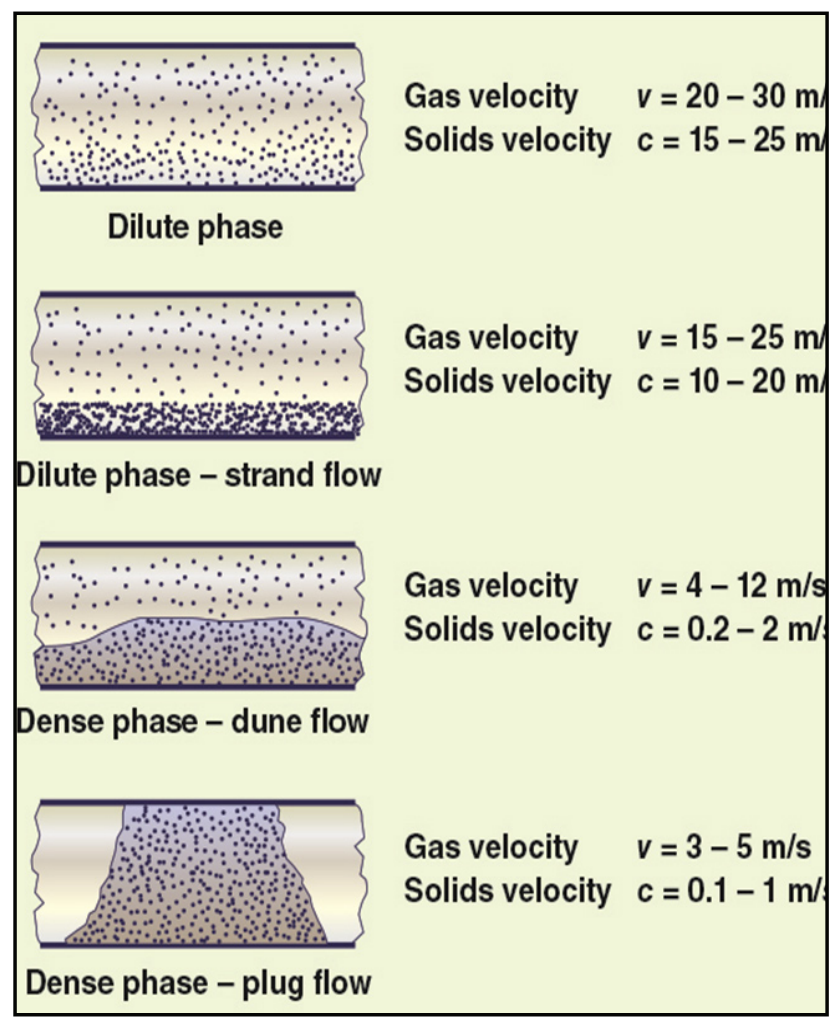

Figure 5: Dependency the speed of grain [02]
Tests by Foster $[05,06]$ indicate that the fracture of the grain is mostly influenced by the speed of air flow through the system and not the speed of moving the grain. Experimental tests for different materials show that the minimum velocity soybeans through a pneumatic system, which is $26.1 \mathrm{~m} / \mathrm{s}$, while below this speed material is very difficult to carried out through the system [06]. Another improvement s related to the transition part (knee) pipe system that the most wear the flow of air and grain mixtures. The solution is reflected in the modification of forms of knee pipe system in order to minimize or largely eliminate the causes of damage to the pipe. In the specific case of expanding the cross-section of the knee creates the effect of slowing the flow of grain and turbulent flow is reduced to laminar (Figure 6). Tests related to such modification knee show that generates much less friction on the turn, impact velocity grains on the walls is also many times smaller and perhaps most importantly, the grains do not collide uncontrollably, and become whole and compact until the end of pipe system (husking). Maintaining continent grains in basic form greatly facilitates the principle of the separation of the outer layer of the grain and thus accelerates the process economy.

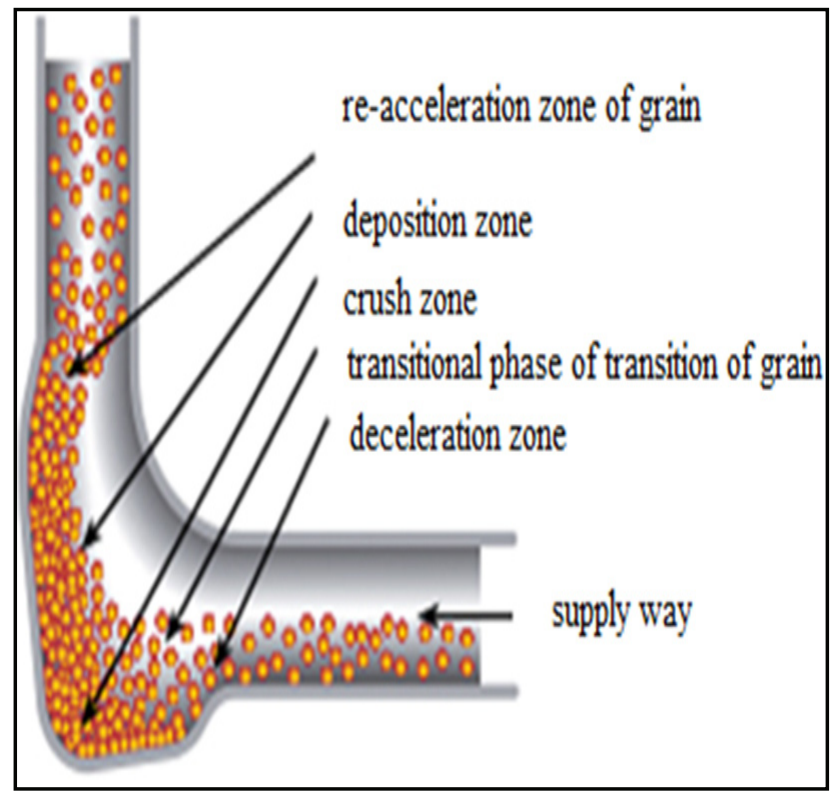

Figure 6: A modified form of the elbow [11] 
Using simulation of virtual pneumatic system in Pipe Flow Expert software (version 7.4) important results were obtain in order to correctly design system. Simulation was conducted for approximate factory conditions of pneumatic system (Table 3) and results shown in the Table 3 are variations of assumed transitions (pneumatic elbows).

Table 3 : Horizontal pipeline parameters of pneumatic system

\begin{tabular}{|c|c|}
\hline a) elbow parameters with radius & b) parameters of modified elbow \\
\hline Flow $=0,1552 \mathrm{~m} 3 / \mathrm{s}$ & Flow $=0,1490 \mathrm{~m} 3 / \mathrm{s}$ \\
\hline Mass Flow $=154,9041 \mathrm{~kg} / \mathrm{sec}$ & Mass Flow $=148,6572 \mathrm{~kg} / \mathrm{sec}$ \\
\hline Velocity $=4,941 \mathrm{~m} / \mathrm{sec}$ & Velocity $=4,741 \mathrm{~m} / \mathrm{sec}$ \\
\hline Length $=35,000 \mathrm{~m}$ & Length $=35,000 \mathrm{~m}$ \\
\hline Inner Diam $=200,000 \mathrm{~m}$ & Inner Diam $=200,000 \mathrm{~m}$ \\
\hline Start Elevation $=0,000 \mathrm{~m}$ & Start elevation $=0,000 \mathrm{~m}$ \\
\hline End Elevation $=0,000 \mathrm{~m}$ & End Elevation $=0,000 \mathrm{~m}$ \\
\hline Start Pressure $=0,70000$ bar.g & Start Pressure $=0,70000$ bar.g \\
\hline End Pressure $=1,9809$ bar.g & End Pressure $=2,2054$ bar.g \\
\hline Total dP Loss $=-13,088 \mathrm{~m} \cdot \mathrm{hd}$ & Total dP Loss $=-15,382 \mathrm{~m} \cdot \mathrm{hd}$ \\
\hline Elevation Change $=0,000 \mathrm{~m}$ & Elevation Change $=0,000 \mathrm{~m}$ \\
\hline Elevation Change Loss $=0,000 \mathrm{~m} . \mathrm{hd}$ & Elevation Change Loss $=0,000 \mathrm{~m} \cdot \mathrm{hd}$ \\
\hline Friction Loss $=3,268 \mathrm{~m} \cdot \mathrm{hd}$ & Friction Loss $=3,016 \mathrm{~m} \cdot \mathrm{hd}$ \\
\hline Entry Fitting Loss $=0,000 \mathrm{~m} \cdot \mathrm{hd}$ & Entry Fitting Loss $=0,000 \mathrm{~m} \cdot \mathrm{hd}$ \\
\hline Exit Fitting Loss $=0,284 \mathrm{~m} \cdot \mathrm{hd}$ & Exit Fitting Loss $=10,146 \mathrm{~m} . \mathrm{hd}$ \\
\hline Pump Suction $=0,7000$ bar.g & Pump Suction $=0,7000$ bar.g \\
\hline Pump Discharge $=2,3275$ bar.g & Pump Discharge $=2,6127$ bar.g \\
\hline Pump Head = 16,629 m.hd & Pump Head = 19,544 m.hd \\
\hline *** Pump Head Outside Curve & *** Pump Head Outside Curve \\
\hline Pump NPSHa $=17,260$ m.hd & Pump NPSHa $=17,260$ m.hd \\
\hline Pump NPSHr = 4,678 m.hd & Pump NPSHr = 4,392 m.hd \\
\hline Pump Efficiency $=52 \%$ & Pump Efficiency $=60 \%$ \\
\hline Pump Power $=48,8 \mathrm{~kW}$ & Pump Power $=47,19 \mathrm{~kW}$ \\
\hline
\end{tabular}

It is significant to notice that friction properties are in decline while mass is going through horizontal pipeline (the same properties that are bad influence on pressure and volume flow). Cause of part damage in system and increasing grain temperature is force of friction during mass movement through pneumatic system. The pressure drop on individual sections is directly proportional to the mass flow velocity and length and inversely proportional to the diameter of the pipe. In order for pressure drop to be lower, it is necessary to reduce the speed of mass movement.

\section{CONCLUSION}

Improving the implementation of grains through the pneumatic system, with the elimination of all negative influences, is the tendency of many scientists and professionals of today. The aim is to provide a mass flow with the necessary capacity by introducing dispensers with continuous flow rather than periodic, as has so far been customary. Controlling the movement of air and flow velocity grains through a pneumatic system leads to a decrease of many defects of the system and thus extend the life span. Modern production conditions assume that the system is not disturbed in any form, in order to maintain continuity of production and minimize losses. Application of modern constructive solutions, especially at crossings, leading to a decrease in the percentage of wear and heating, as mass flow, and the piping system and thus reduce grain breakage 
during transport. All this requires continuity of mass flow and maintenance of production processes within the limits desirable.

In this paper with proposed solution on elbows it is shown that it is possible to reduce mass flow velocity by 10 percent without clogging the process and stops in grain material transport.

Savings in electric energy consumption by working hour can be seen in used power needed for pneumatic system. With modified shape of elbow required power of blower is $P=47,19 \mathrm{~kW}$ (savings of approximately 3 percent comparing to elbow with radius).

\section{REFERENCES}

1) Aptec Powder Systems, (2015) Advance in Pneumatic Conveying, Unit 1, England, 1-17.

2) Bathia, A. (2010) Pneumatic Conveying System, Course No: MO5-010, Continuing Education and Development, NY, 1-57.

3) Bell M. J. (2015) pneumatically conveying fragile materials without particle Degradation, Powder Show \& Conference, Atlanta, GA, 37-44.

4) Callister, W. (2007) Materials Science and Engineering, seventh edition, Characteris- tics, Applications and Processing of Polymers: The University of Utah, Department of Metallurgical Engineering, John Wiley \& sons, 523-571.

5) Foster, G.H, (1973) Grain breakage caused by commercial handling methods, USDA Market Research Report No. 968.

6) Haw, J. (1993) Pneumatic conveying of grains, Pac. Agri, (4), 1-13.

7) Internal documents of the company "Dijamant" from Zrenjanin.

8) Tolmač, D., Prvulović, S. (2012) Transportni sistemi, Zrenjanin: Univerzitet u Novom Sadu, Tehnički fakultet "Mihajlo Pupin", 132 str.

9) Šešlija, D. (2010), Fabrička automatizacija, deo 1, Novi Sad: Univerzitet u Novom Sadu, FTN, 130 str.

10) www.foxvalve.com, catalogue, retrieved on December $7^{\text {th }}, 2016$.

11) www.pelletroncorp.com, retrieved on December $7^{\text {th }}, 2016$

Paper sent to revision: 17.12.2016.

Paper ready for publication: 10.07.2017. 